\title{
EXPERIMENTAL STUDY OF RELATIVE DENSITY EFFECT ON BEARING CAPACITY OF SAND REINFORCED WITH GEOGRID
}

\author{
Noor A. Fakher ${ }^{1}$ and Mohammed K. Fakhruldin ${ }^{2}$ \\ ${ }^{1}$ MSc. Student, Civil Engineering Department, Faculty of Engineering, University of \\ Kufa, Najaf, Iraq. Email: noora.alnafakh@student.uokufa.edu.iq \\ 2 Asst. Prof., Ph.D, Civil Engineering Department, Faculty of Engineering, University of \\ Kufa, Najaf, Iraq. Email: mohammed.fakhruddin@uokufa.edu.iq \\ HTTP://DX.DOI.ORG/10.30572/2018/KJE/120304
}

\begin{abstract}
Reinforced soil technology is considered one of the most important methods of soil improvement due to its simplicity and speed in implementation and saving cost. In this research a strip footing and geogrid (Tensar SS2) were used to reinforced sandy soil and investigated the effect of relative density on bearing pressure and compressibility. The soil was strengthen with four layers of (geogrid Tensar SS2) and used a five relative densities were $(30.7 \%, 49.7 \%$, $56.5 \%, 64 \%$, and $75.9 \%$ ) to include cases of loose, medium and dense sand. The results also showed the effect of relative density on the bearing capacity and the settlement as experimental tests indicated that increasing the relative density from $30.9 \%$ to $64 \%$ gave an improvement in soil bearing capacity, as well as an effective improvement in carrying capacity when increasing the relative density from $64 \%$. The results showed that the bearing capacity when using relative densities of $49.7 \%, 56.5 \%, 64 \%, 75.9 \%$ increased by $1.218,1.287,1.512$, and 2.1799 , respectively, of the bearing capacity of reinforced soils with relative density of $30.7 \%$. As for the effect of relative density on the settlement, it was found that the settlement is generally less in the case of soil with higher relative density.
\end{abstract}

KEYWORDS: Geogrid, Relative density, Strip footing, Sandy soil. 


\section{INTRODUCTION}

The soil reinforcement gets a long tradition in the previous literature. Earlier mention of reinforcement of soil belong to the Sumerians under King Kurigalzu I, who elevated the AqarQuf temple in Mesopotamia at the north of Bagdad city dated back to 3500 years ago. The Sumerians were aware regarding the importance of both soil and brickwork that they had almost no strength in tension and reinforcing elements into their constructions were necessary to enhance the tensile forces for stabilization (Ziegler, M. 2017). The footing standing on weak soil, has decrease bearing capacity shows increase settlement below small loads. One of the important missions of geotechnical engineers is the upgrading in strength features or variables of soil. To accomplish this task, the investigators assessed techniques of ground-upgrading to elevate the bearing capacity of soil (Patil and Rakaraddi, 2015). "The appropriate definition of soil reinforcement is "a construction material consisted of cohesionless free drainage materials, which is strong in compression but weak in tension, and the reinforcing elements, with high tensile strength materialsn (Singhvi, Arora and Veerwal 2017).

\section{MATERIAL}

\subsection{Sand}

The Table 1 summarized the all properties of sand which are used in this studies. While Fig. 1. depicted the grain size distribution of sand and classified as poorly graded (SP) in accordance to the Unified Soil Classification System (USCS).

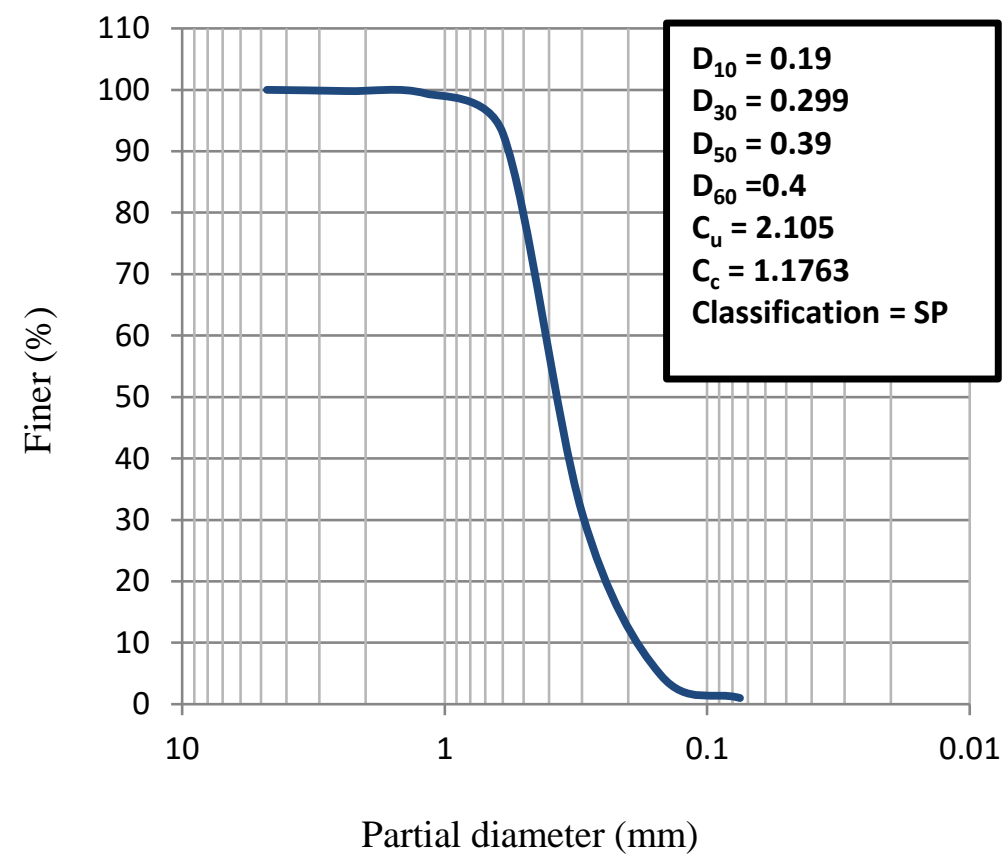

Fig. 1. Grain size distribution curve of the sand. 
Table 1. Physical and Chemical Properties of the sand used.

\begin{tabular}{|c|c|c|c|c|c|c|}
\hline Soil property & \multicolumn{5}{|c|}{ Results } & Specification \\
\hline Effective size, D10 & \multicolumn{5}{|c|}{190 (mic) } & \\
\hline D30 & \multicolumn{5}{|c|}{299 (mic) } & \\
\hline D50 & \multicolumn{5}{|c|}{390 (mic) } & \\
\hline D60 & \multicolumn{5}{|c|}{400 (mic) } & ASTM D 422 \\
\hline Coefficient of uniformity $\left(C_{u}\right)$ & \multicolumn{5}{|c|}{2.105} & \\
\hline Coefficient of curvature $\left(C_{C}\right)$ & \multicolumn{5}{|c|}{1.176} & \\
\hline Specific gravity $\left(\mathrm{G}_{\mathrm{S}}\right)$ & \multicolumn{5}{|c|}{2.61} & ASTM D 854 \\
\hline Max. dry unit weight $\left(\gamma_{d \max }\right)$ & \multicolumn{5}{|c|}{$17.658 \mathrm{KN} / \mathrm{m}^{3}$} & ASTM D 4253 \\
\hline Min. dry unit weight $\left(\gamma_{d \min }\right)$ & \multicolumn{5}{|c|}{$14.59 \mathrm{KN} / \mathrm{m}^{3}$} & ASTM D 4254 \\
\hline Max. void Ratio, $\left(e_{\max }\right)$ & \multicolumn{5}{|c|}{0.754} & - \\
\hline Min. Void Ratio, $\left(e_{\min }\right)$ & \multicolumn{5}{|c|}{0.45} & - \\
\hline Water content, $\%$ & \multicolumn{5}{|c|}{6.56} & ASTM D 2216 \\
\hline Relative density $\left(D_{r}\right) \%$ & 30.7 & 49.3 & 56.5 & 64 & 75.9 & \\
\hline friction Angle ( $\varnothing$ used $)$ & 27.89 & $31.8^{\circ}$ & $33^{\circ}$ & $35^{\circ}$ & $43^{\circ}$ & SATM D 3080 \\
\hline Dry unit weight used,(KN/m3) & 15.4 & 15.9 & 16.2 & 16.4 & 16.8 & - \\
\hline Void Ratio, e & 0.66 & 0.603 & 0.58 & 0.55 & 0.523 & - \\
\hline Organic material & & & 1.4 & & & \\
\hline Gypsum content, $\%$ & & & 2.7 & & & BS.1377(1967) \\
\hline T.D.S., (mg/L) & & & 1150 & & & \\
\hline
\end{tabular}

\subsection{Geogrid}

Table 2 summarized the porperties of the Tensar SS2 used in this study, (Al-Omari and Fekheraldin, 2012).

Table 2. The properties of geogrid Tensar SS2 (Al-Omari and Fekheraldin, 2012).

\begin{tabular}{ccc}
\hline Characteristics & loneliness & Results \\
\hline Grid type/color & - & Rectangle/black \\
Aperture size (MD/XMD) & $\mathrm{mm}$ & $28 / 40$ \\
Mass /unit area & $\mathrm{kg} / \mathrm{m}^{2}$ & 0.3 \\
Thickness of Rib & $\mathrm{mm}$ & $1.2 / 1.1$ \\
Thickness of Junction & $\mathrm{mm}$ & 3.9 \\
ultimate tensile resistance & $\mathrm{kN} / \mathrm{m}$ & $14.4 / 28.2$ \\
modulus of Elasticity & $\mathrm{N} / \mathrm{mm}^{2}$ & $570 / 990$ \\
Tensile strength & $\mathrm{N} / \mathrm{mm}^{2}$ & $24 / 30.7$ \\
Percentage elongation at max load & percent & $3.5 / 2.9$ \\
\hline
\end{tabular}




\section{LOADING FRAME}

The Fig. 2 illustrated the all details of model of container and strip footing and loading frame.

Strip model footing has been produced from a thick plate with dimensions $(490 * 135 * 40 \mathrm{~mm})$, for length, wide and high respectively, while the thickness (10) $\mathrm{mm}$ to represented rigid steel plate. The sand container had been made by (Fakhraldin, 2013) to contain the soil, with dimensions $(1000 * 500 * 700 \mathrm{~mm})$ in length, width and depth respectively.

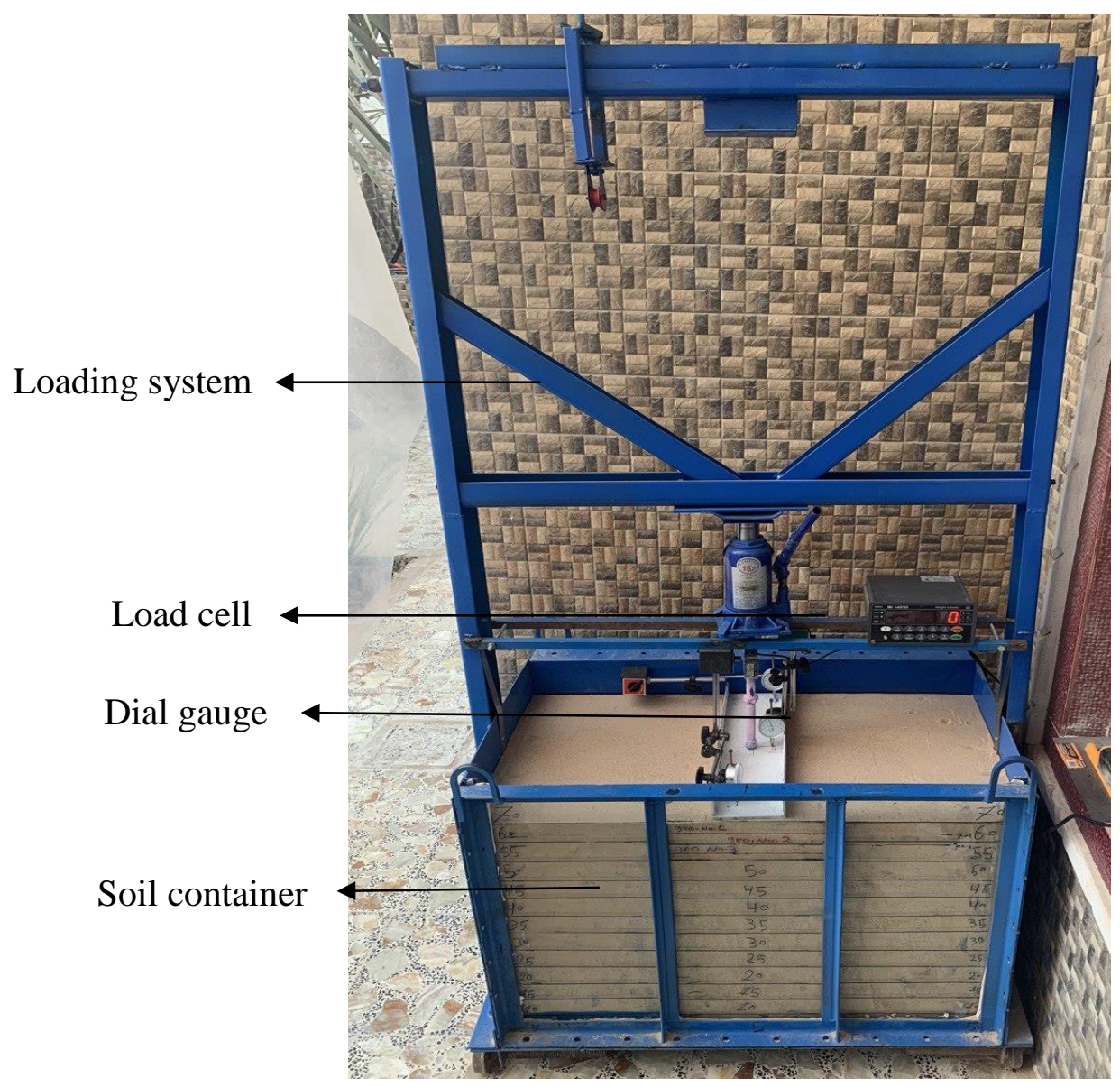

Fig. 2. Loading frame and model.

\section{SAND PREPARATION}

To achieve and represented the all soil state including soft, medium and stiff of sand in container which required device to raining the sand, (Turner and Kulhawy, 1987). Fig. 3 depicted the relative density of $30.7 \%, 49.35 \%, 56.5 \%, 64 \%, 75.9 \%$ will be $10 \mathrm{~cm}, 30 \mathrm{~cm}, 40 \mathrm{~cm}$, $50 \mathrm{~cm}$, and $70 \mathrm{~cm}$ respectively. The relative density was choosing at $30.7 \%, 49.35 \%, 56.5 \%$, $64 \%$, and $75.9 \%$ to covered loose, medium, and dense sand. 


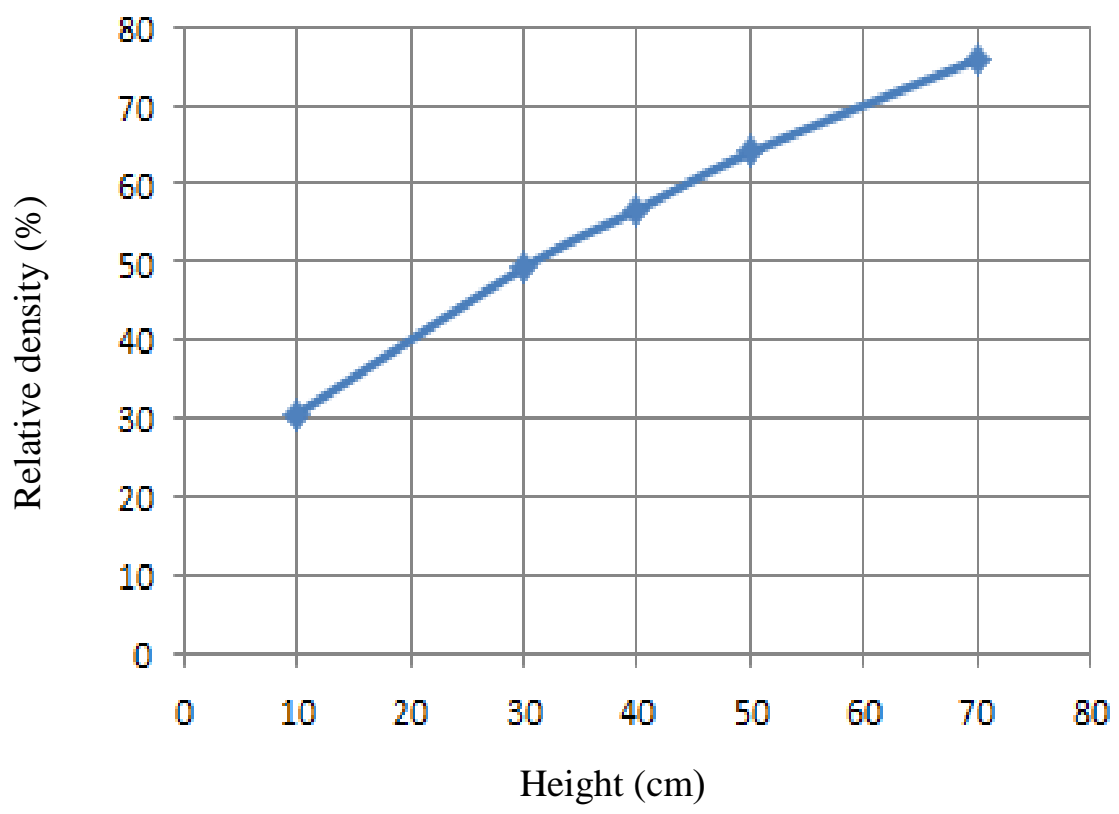

Fig. 3. Relative density controlled.

\section{GEOGRID PREPARATION}

The distribution geegrid layers in the model are depicted in Fig. 4

The values of $(\mathrm{u})$ equal to $(\mathrm{B} / 4)$ and the distance between reinforcement layers $(\mathrm{h})$ considered 0.1875 B, Fakhraldin (2013), while the depth of last reinforced layer was conducted according to the following equation

$\mathbf{d}=\mathbf{u}+(\mathbf{N}-\mathbf{1}) * \mathbf{h}$

Where

$\mathrm{N}$ : layer numbers

In this study used $\mathbf{u}$ equal to $\mathrm{B} / 4 ; \mathrm{h}=0.1875 \mathrm{~B}$; and $(\mathrm{N})$ equal to 4 . 


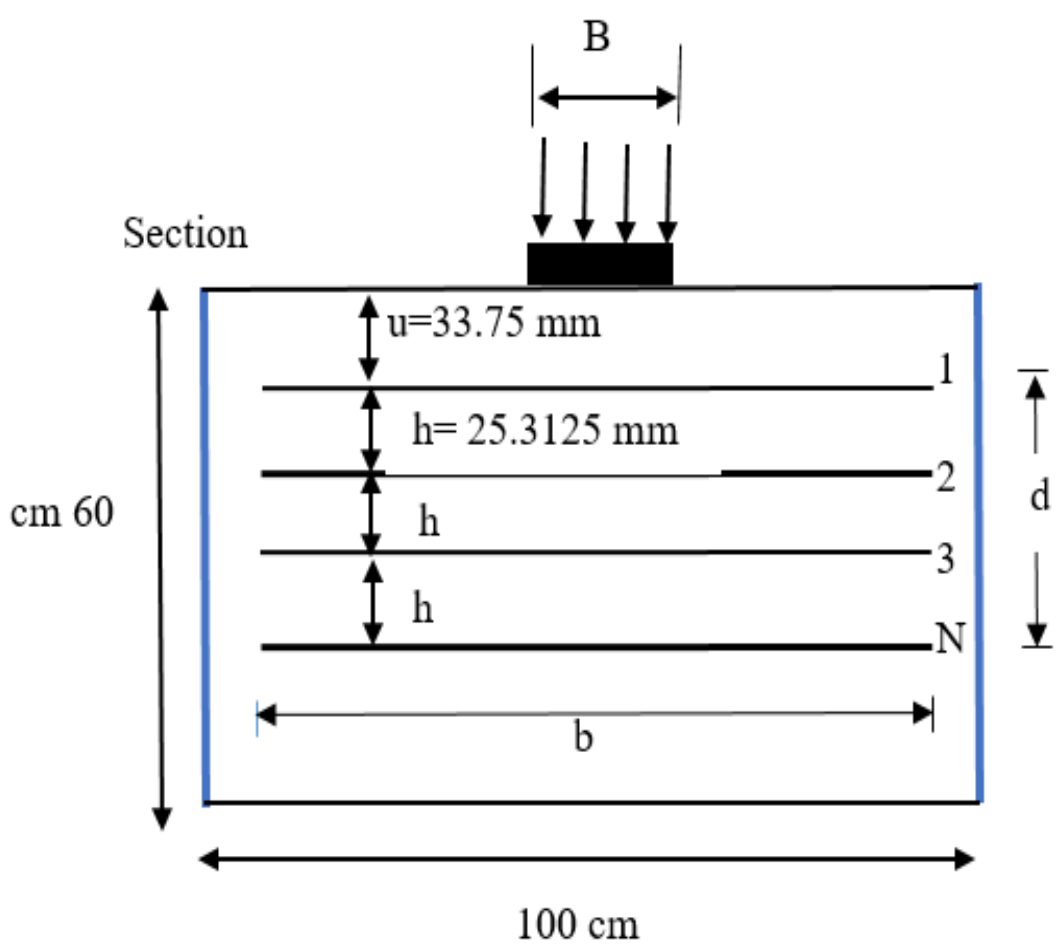

Fig. 4 Distribution of geogrid in the model.

\section{WORKING STEPS}

The steps of this work program were summarized in the following:

Step one: It includes the chemical and physical characteristics of the soil

1. Physical characteristics include: Sieve analysis, minimum and Maximum density, internal friction $(\varnothing)$, Specific gravity, and Water content.

2. Chemical characteristics: the content of Gypsum, (T.D.S), and $\mathrm{SO}_{3}$ content.

Step two: It include testing the reinforced soil under strip footing. the parametric studies include; five relative densities $(30.7 \%, 49.35 \%, 56.5 \%, 64 \%$, and $75.9 \%),(D f=0), \mathrm{u}=0.25 \mathrm{~B}$, $\mathrm{h}=0.1875 \mathrm{~B}$ and $\mathrm{N}=4$.

\section{RESULTS AND DISCUSSIONS}

The first layer of the reinforcement had been with a depth $(\mathrm{u})$, which was being of about $0.25 \mathrm{~B}$, the depth of second layers (h) was $0.1875 \mathrm{~B}$ from the first layer, the depth of third layers $(\mathrm{h})$ was $0.1875 \mathrm{~B}$ from the second layer, and the depth of fourth layers was $0.1875 \mathrm{~B}$ from the third layer, the B is the footing width. The tests were conducted on the heights of dropping equals to $(10,30,40,50$, and 70$) \mathrm{cm}$ the relative density were $30.7 \%, 49.35 \%, 56.5 \%, 64 \%$, and $75.9 \%$. The bearing pressure and load-settlement relation had been presented in Fig. 5. Similarly, the 
ultimate bearing capacity which had been gated from the model tests and the compressibility had been summarized in Table 3. The marked of the point of ultimate bearing capacity on the curve of the load settlement had been performed with easily, where the test was straincontrolled, beside to the clear vision of the peak.

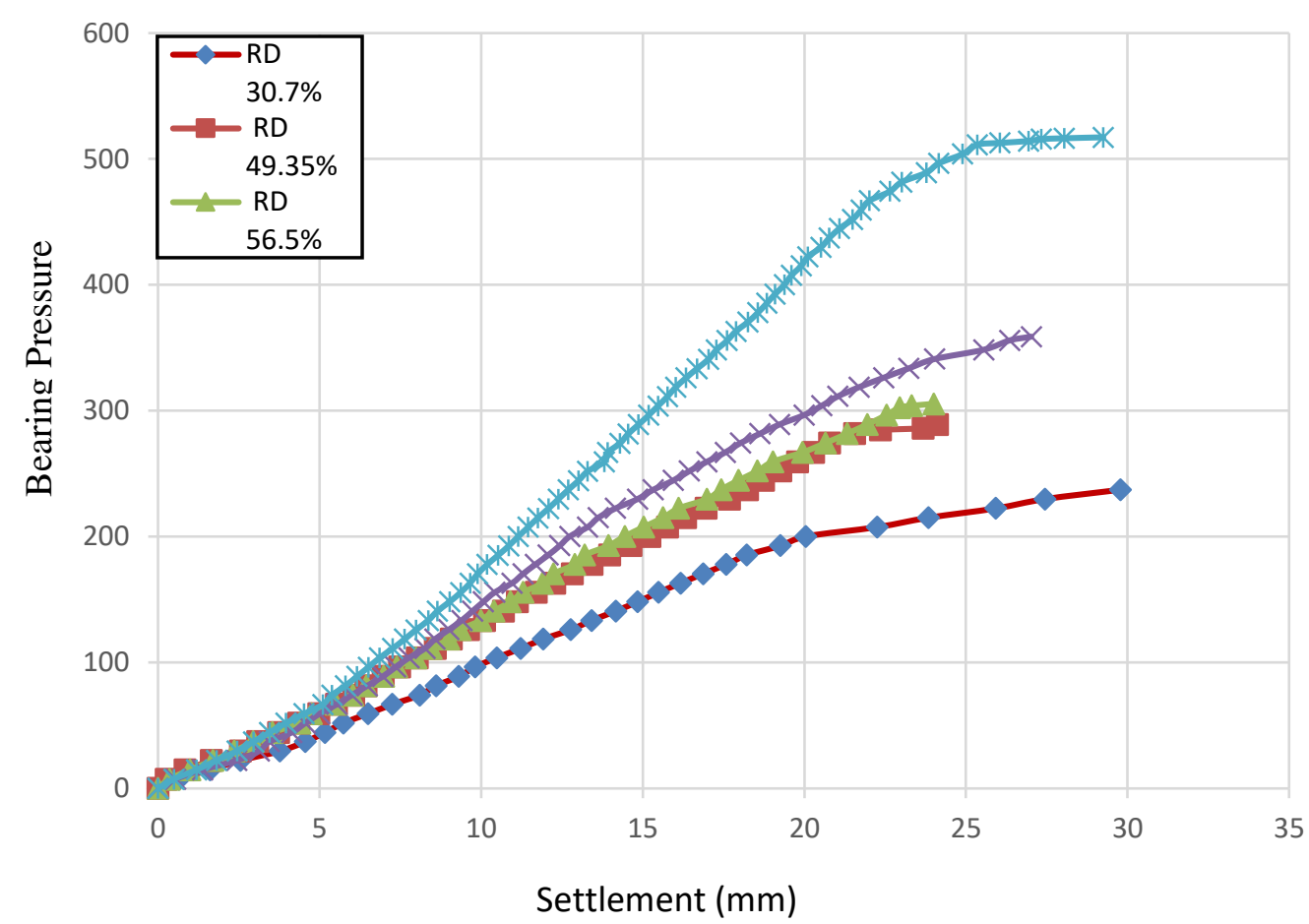

Fig. 5. Bearing pressure versus settlement for fourth layers of geogrid Tensar SS2.

Table 3. Ultimate bearing pressure and compressibility for fourth layers of geogrid.

\begin{tabular}{cccccc}
\hline $\begin{array}{c}\text { Test } \\
\text { No. }\end{array}$ & R.D \% & $\begin{array}{c}\text { (qult)R } \\
\text { KPa }\end{array}$ & $\begin{array}{c}\text { Max. } \\
\text { settlement(mm) }\end{array}$ & $\begin{array}{c}\text { Improvement } \\
\text { in B.C (\%) }\end{array}$ & $\begin{array}{c}\text { Decrease in } \\
\text { settlement (\%) }\end{array}$ \\
\hline 1 & 30.7 & 237.26 & 29.78 & - & - \\
2 & 49.35 & 289.16 & 24.12 & 1.2187 & 1.6326 \\
3 & 56.5 & 305.47 & 24.01 & 1.287 & 1.709 \\
4 & 64 & 358.86 & 27.02 & 1.512 & 1.943 \\
5 & 75.9 & 517.218 & 29.25 & 2.1799 & 2.346 \\
\hline
\end{tabular}

\subsection{Effective of Relative Density on the Bearing Pressure}

The tests that have been carried out in reinforced sand by 4 layers of Tensar SS2 giving rise to the following findings that have been illustrated in Fig 6, findings have been illustrated for relative densities of $30.7 \%, 49.35 \%, 56.5 \%, 64 \%$, and $75.9 \%$. In synchronize with previous literature, it can be showed that increasing the relative density from $30.9 \%$ to $64 \%$ will lead to 
a bigger load capacity at every settlement level. On the other hand, increasing from $64 \%$ to $75.9 \%$ will lead to an even more striking increment.

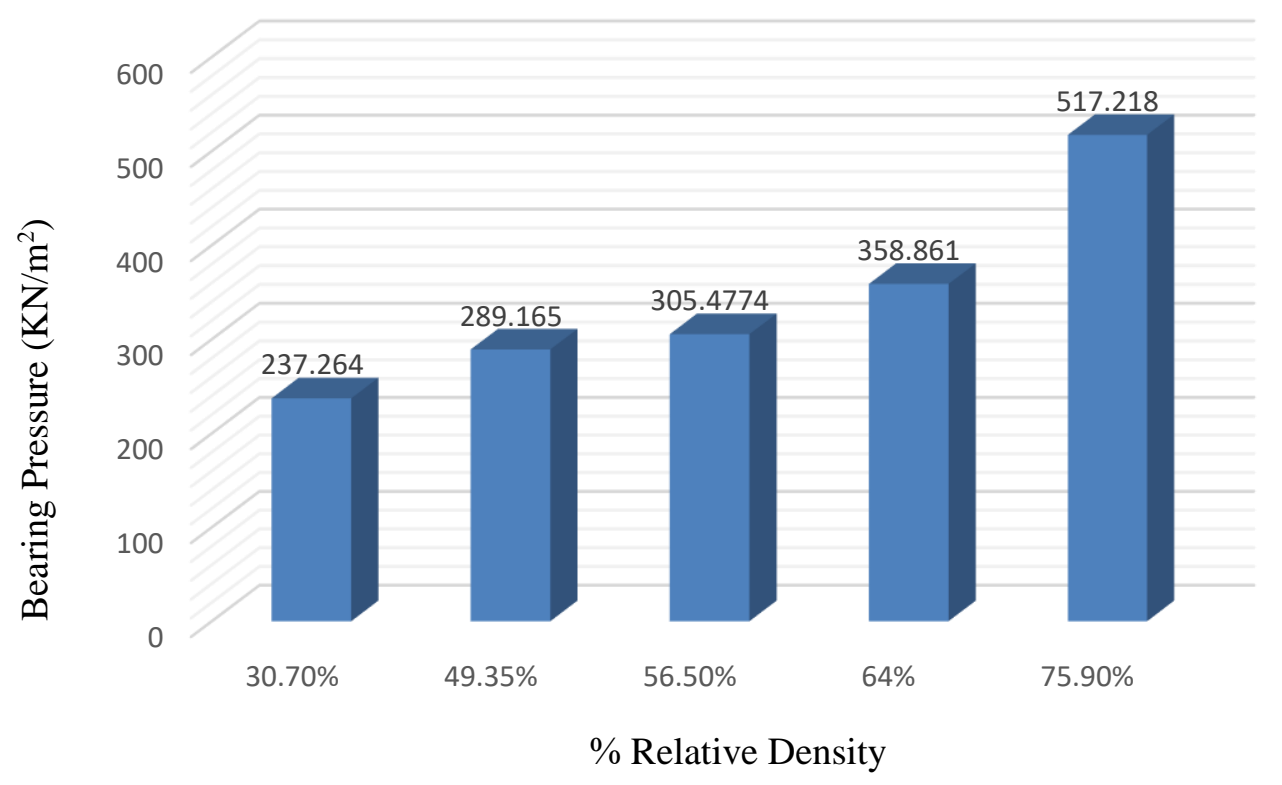

Fig. 6. Effective of relative density on the bearing pressure for four layers of geogrid Tenasr SS2.

\subsection{Effective of Relative Density on the Settlement}

In Fig. 7 the settlement is reducing when the soil density is increasing. This result, can be attributed to the end anchorage increment from the soil which withstands the downward deflection of the geogrid Tenasr SS2 rank, which caused of incremental effective of the enhancement. 


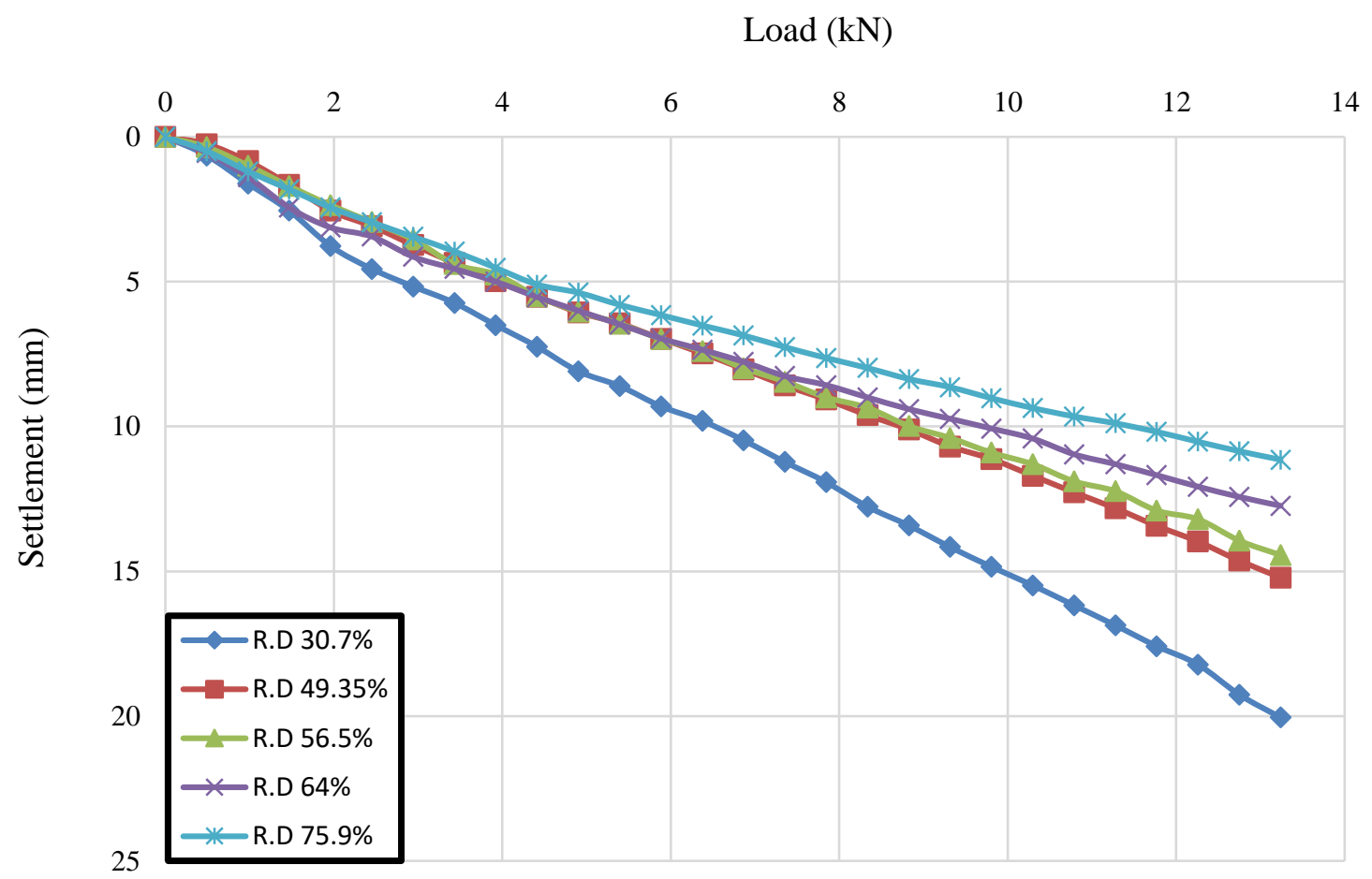

Fig. 7. Load versus settlement for fourth layers of geogrid Tensar SS2.

\section{CONCLUSION}

The following conclusions can be drawn from this study

1. It can be concluded that the increment of the relative density from $30.9 \%$ to $64 \%$ led to a higher load capacity at each level of settlement, while the increment from $64 \%$ to $75.9 \%$ caused of an extra dramatic increment. Also, for the effective of relative density on the settlement, it can be concluded that the settlement is generally found to be lower for higher density of soil.

2. The bearing capacity of sand increased about 237.26, 289.16, 305.47, 358.86 and $517.218 \mathrm{kPa}$ after strengthen sand by four layers of geogrid Tensar SS2 with relative densities were $30.7 \%, 49.35 \%, 56.5 \%, 64 \%$, and $75.9 \%$ respectively. It is showed that the bearing pressure of sand was increased after increased the relative density about $1.218,1.287,1.512$, and 2.1799 the reinforced sand's bearing capacity by relative density $30.7 \%$.

\section{REFERENCES}

ASTM D2216-2010, "Standard Test Method for Laboratory Determination of water (moisture) content of soil and Rock by Mass".

ASTM D3080-1998, "Standard Test Method Direct shear test”. 
ASTM D422-63, 2007, "Standard Test Method for Particle Size-Analysis of Soils".

ASTM D4253-2007, "Standard Test Method for Maximum Index Density and Unit Weight of Soils Using a Vibratory Table".

ASTM D4254-2007, “Standard Test Method for Minimum Index Density and Unit Weight of Soils and Calculation of Relative Density".

ASTM D854-05, 2007, “Standard Test Method for Specific Gravity of Soil Solids by Water Pycnometer".

BS 812, (1988) and ICS 91.100.15 71.080.01 19.020, manual 895/2003, “Testing Aggregates”, Part 118, Method for Determination of Sulphate Content.

Budania, R., Arora, R. P., Singhvi, B. S., \& Veerwal, H. K. (2017), "Experimental study of rectangular footing resting over geo-grid reinforced sand" Development, 4(1).

Fakhraldin M. K., (2013), "Properties Measurements and Applications of some Geogrids in Sand", PhD Thesis, Alnahrain University.

Patil, S., \& Rakaraddi, P. G. (2015), “The Load Carrying Capacity of Square Footing Resting On Reinforced Sand" IJRET: International Journal of Research in Engineering and Technology04, 2321-7308.

Raid R. Al-Omari and Mohammed K. Fekheraldin, (2012), "Measurement of Tensile Properties of Geogrids”, Environment, Kuala Lumpur, Malaysia.

Turner J. R. and Kulhawy F. H., (1987), "Experimental Analysis of Drilled Foundations Subjected to Repeated Axial Loads under Drained Conditions", Report EL-S32S, Electric Power Research Institute, Palo Alto, California.

Ziegler, M. (2017), “Application of geogrid reinforced constructions: history, recent and future developments" Procedia Engineering, 172, 42-51. 